\title{
Reinforcement of brick historic buildings threatened by structural damages or by failure
}

\author{
Leopold Kruszka,* \\ Faculty of Civil Engineering and Geodesy, Military University of Technology, Warsaw, Poland. ${ }^{2}$
}

\begin{abstract}
The paper presents selected aspects of reinforcing the brick cultural heritage buildings, particularly load-carrying elements of those structures. In some cases the operational phase of many load-bearing elements of the historical buildings is shrinking or has used up. The crucial task while carrying out construction works related to reinforcing or repair of the load-bearing structure is to ensure safety. This safety should be assured regarding both the structure itself and its users. The design concept also needs to include recommendations and instructions of the conservatorinspector. The proposed scope of technical assessment and analysis of the load-bearing structures of buildings is presented on selected examples. The performed diagnostics process allowed to properly determine the occurred hazards and on this basis to properly design and carry out repair of damaged elements of structure [1]. The first of the analysed cases concerns the barracks facility near the Makowiecka Street in Przasnysz. Another example described in this paper is the brick dome of the church building of St. Anne in Wilanów district in Warsaw. The damages and failure identification process, as well as taken measures and proposed methods of reinforcement of the structure are presented with reference to the both above mentioned examples.
\end{abstract}

\section{Introduction}

The renovation of historic buildings requires the selection of design solutions to achieve the assumed effects while ensuring the effectiveness of repairs. Most often recommendations and instructions of the conservator-inspector for heritage buildings in Poland relate to preventing the original building blocks of the structure, the shape and the appearance of the repaired elements from being changed $[1,2,3]$. A common case is the formation of scratches and cracks in masonry elements of load-bearing structures. This type of structural damage in the load-bearing walls may arise as a result of differential foundation settlement, local exceeding of admissible stresses (eg increasing the operational load), loss of stability and longitudinal stiffness of the walls and also due to thermal stresses caused by temperature changes [3]. Issues concerning the renovation process of the dome of the historic St. Anne's Church in Wilanów (Warsaw), as well as the army barracks in Przasnysz $[1,4]$ are discussed in this paper.

\footnotetext{
${ }^{*}$ Corresponding author: leopold.kruszka@,wat.edu.pl
} 


\section{Description of the technical condition of buildings}

\subsection{Army barracks in Przasnysz}

The barrack and training building No. 10 was built in 1912 and is listed in the Regional Heritage List. It is a non-basement, three-story building with a brick structure. The building has Klein ceilings with arched cylindrical brick vaults, as well as wooden ceilings. The building's cubic capacity is $27029 \mathrm{~m}^{3}$, while its total area is $5095 \mathrm{~m}^{2}$.

The walls of the building are made of solid ceramic bricks. In the central part of the building, the technical condition of these walls was defined as good. However, in the corners and on the tops of the building numerous cracks on the entire thickness of the wall were diagnosed. Wall partitions in sanitary rooms located in the gable parts were particularly cracked and scratched. The examples of these damages are shown in Fig. 1.

a)

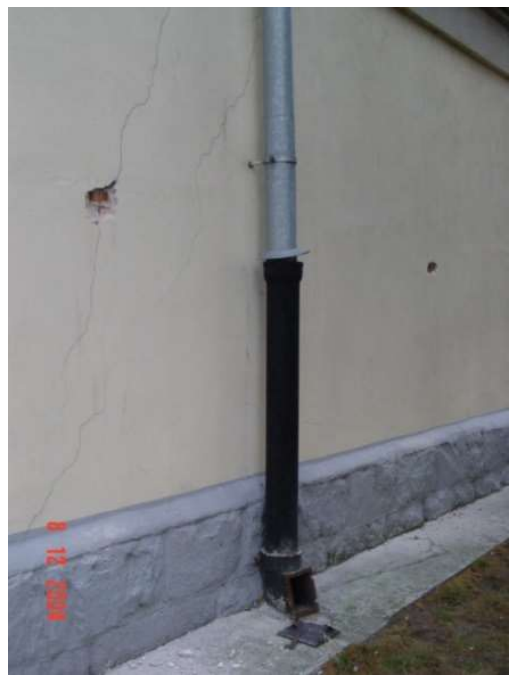

b)

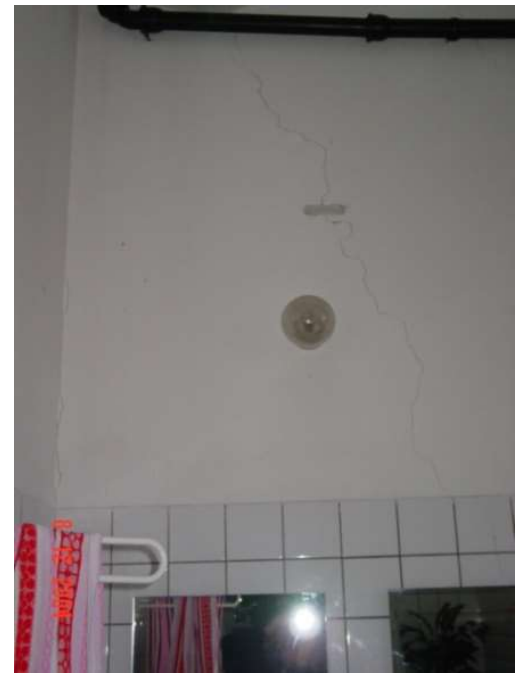

Fig. 1. Examples of damages to the barracks building in Przasnysz: a) on the gable wall facade, b) in the sanitary room.

It should be mentioned that the repair in the form of surface reinforcement of the cracked and scratched gable walls of the building had already been recommended in the structure design of the renovation, which was made in 1997. However, no renovation works were carried out according to the recommendations.

\subsection{Church of St. Anna in Warsaw (Wilanów district)}

The Church of St. Anna in Warsaw (Wilanów district) was built in 1772 according to the design of Jan Kotelnicki, the view is shown in Fig. 2. It was founded by Prince August Czartoryski, the owner of the Wilanów estate of that time and rebuilt in 1857-1870 by Henryk Marconi, in cooperation with Leonardo Marconi and Jan Hussan. At the behest of Aleksander and August Potocki, the baroque style of the church was changed into a neo-renaissance style. 


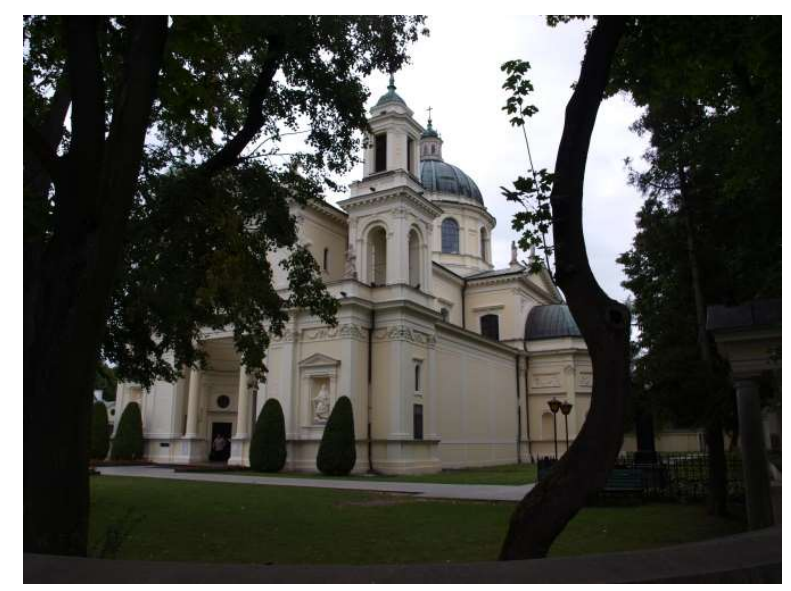

Fig. 2. Church of St. Anna in Warsaw (Wilanów district).

The church's structure is made of solid red bricks in a three-nave layout. The middle nave is based on pillars. Church's ceramic brick dome with a diameter of $11.4 \mathrm{~m}$ is based on four pillars and vertical walls with windows with arch lintels. It consists of a cylindrical section and a dome supported on its upper edge. In the cylindrical section of the dome there are peripherally window openings vaulted with segmented arches. Between the dome's spherical cap and its cylindrical section there is a cornice that fulfils the function of a ring fastening the base of the dome.

At the beginning of the present century, the visible scratches on the elevation and inside the church began to appear. The scope and location of these damages forced repairs to be carried out to ensure the safety of the structure and the safety of users of this historic building. The numerous quantity of cracks and scratches occurred in the outline of pillars supporting the dome, in arched windows and along the outer longitudinal walls. Additionally, from the inside, small scratches appeared on the entire surface of the dome. The examples of damage found are shown in Fig. 3 and Fig. 4.

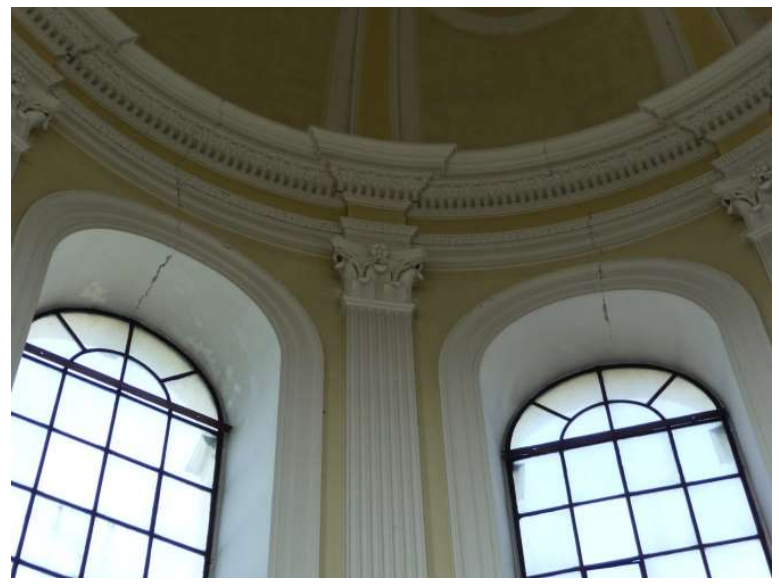

Fig. 3. Cracks in arched window vaults of the church of St. Anne in Wilanów. 


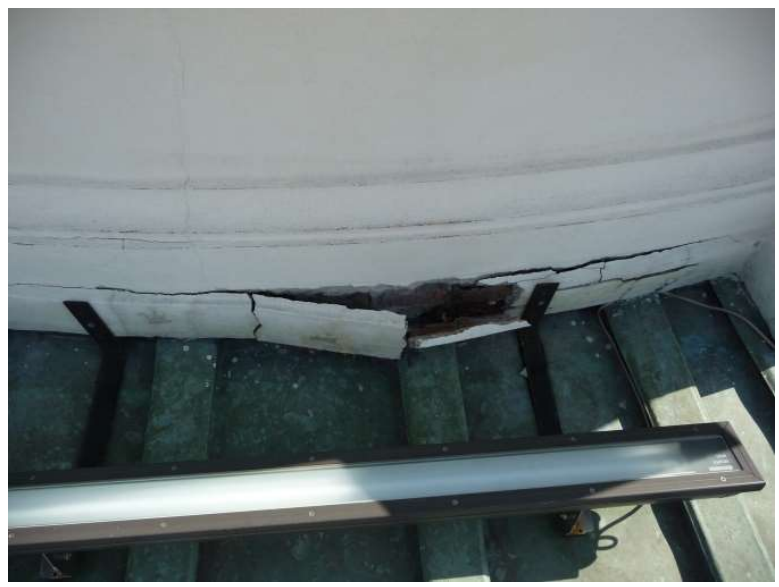

Fig. 4. Cracks of cornices and cracks on the facade of the dome of the church of St. Anne in Wilanów.

The location, historical character, as well as the function of the object in the form of a church, means that a large number of visitors can stay in the facility and its surroundings. This implies the need to ensure complete safety of the structure and its users.

\section{Analysis of the causes of damage and proposal of repair works}

\subsection{Army barracks in Przasnysz}

The cause of the damage is the location of the absorptive septic tanks in the very close vicinity of the gable walls resulting in excessive settle of the building foundations. The lack of tie beams on individual floors of the army barracks has also contributed to the further propagation of cracks in the inter-floor levels of the building. Cracks in the brick walls have reached a width of up to $10 \mathrm{~mm}$, have a cruising character and pose a real threat to the safety of the load-bearing elements of that historic building.

As the solution of repairing damaged, cracked load-bearing walls of the building, the surface reinforcement on both sides with steel rods with a diameter of $10 \mathrm{~mm}$ and a length of min. $1 \mathrm{~m}(0.5 \mathrm{~m}$ on each side scratch) is proposed. Before wall reinforcement, all scratches and cracks are filled with cement mortar injection, then plaster should be removed on both sides to a height of $0.5 \mathrm{~m}$ below and above occurred damages - Fig. 5. Surface reinforcement of the scratched and cracked external walls should be done at least, every third joint, which should be cleaned at a depth of about $2 \div 3 \mathrm{~cm}$ and then filled with cement mortar. Additionally, the steel rods of the appropriate length must be placed in previously injected mortar. Finally, after setting the cement mortar the wall should be plastered. It is also recommended that the scratches and cracks visible on the ceilings of inter-storey floors should be filled with cement mortar injections.

For the cracked window lintels, reinforcement in the form of steel angle bars is proposed - Fig. 6. Steel angles with cross-section L $35 \times 35 \times 4 \mathrm{~mm}$ need to be anchored on $\min .25 \mathrm{~cm}$ piers, on both sides of the window hole. First, the scratches are filled with cement mortar, then the plaster at the window lintel should be removed and grooves should be made to insert the angle bar. Then the lintel formwork should be made. Before installing the angle bar, the grooves must be cleaned and rinsed with cement mortar. Finally, a steel beam is inserted and then it is sealed with cement mortar. 


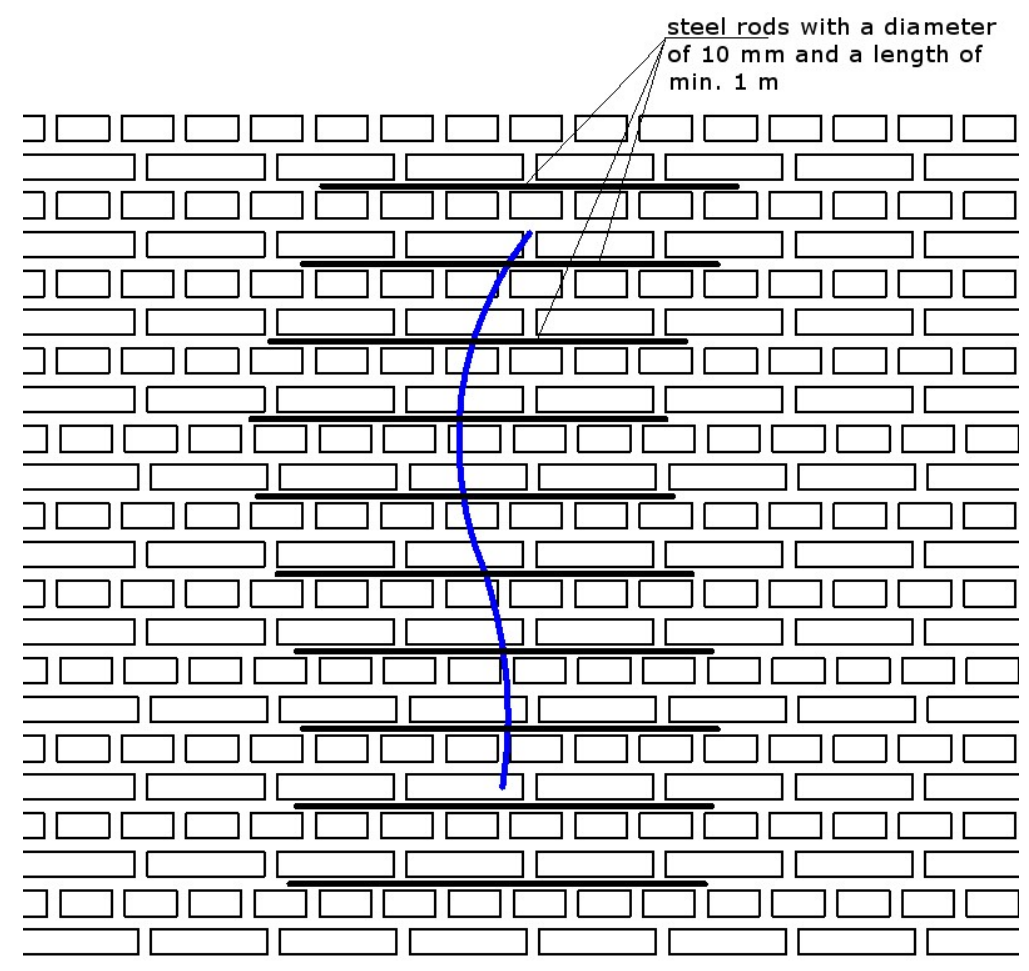

Fig. 5. The method of the surface reinforcement of the cracked load-bearing walls of the building.

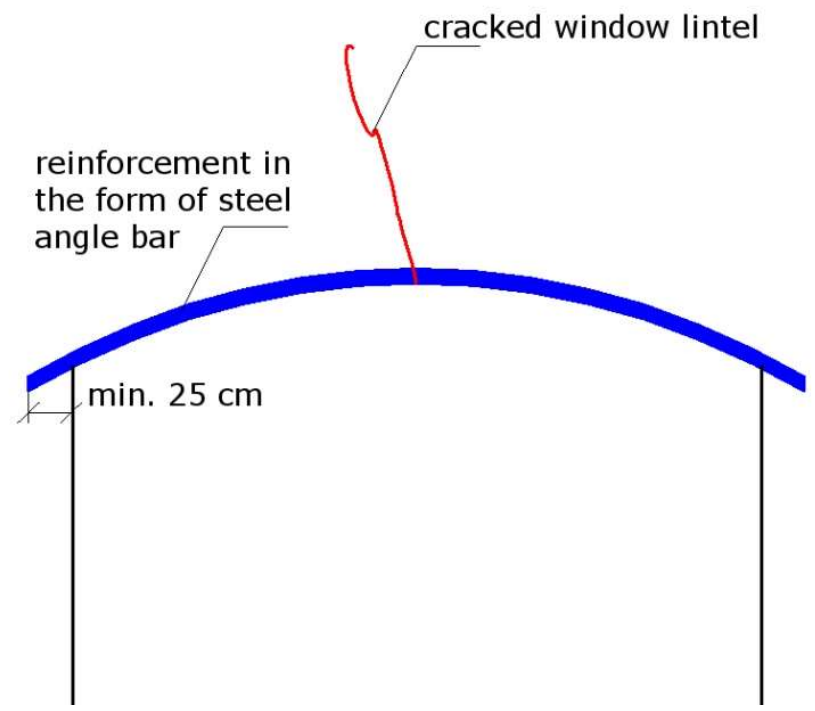

Fig. 6. The method of the reinforcement of the cracked window lintel.

The window lintels should be repaired starting from the storey located the lowest up to the top storey. 


\subsection{Church of St. Anna in Warsaw (Wilanów district)}

The reduction in the level of groundwater is identified as the main cause of damage to the dome of the church. This phenomenon resulted in an increasing value of effective stresses of soil and additional settlement of the church foundation. The effect was related to deep earthworks made near the church, which cut through the groundwater runoff towards the Vistula river. The design works began with a very detailed analysis and assessment of the technical condition of the structure in terms of identifying damage occurred and determining the methods and technology of repair works. As a result, a repair plan was created, the purpose of which was to remove the occurring cracks and scratches of the masonry elements.

Firstly, it was recommended to reinforce the dome drum by placing tape of CFRP strips over the windows [5]. The reinforcement was designed in the form of perimeter reinforcement in the bands above the windows in the cylindrical part of the dome, which was realized in the form of two double CFRP strips glued on the outer side of the dome at its full circumference. Piercing of the pilasters was necessary for a proper application of the tapes. However, this minimized the risk of damage to the dome's structure and ensured minimal interference in the structure of this historic building - Fig. 7. Such a method made it difficult to obtain the required tape tension, but it ensured the least possible interference in the structure of this historic church $[4,5]$.

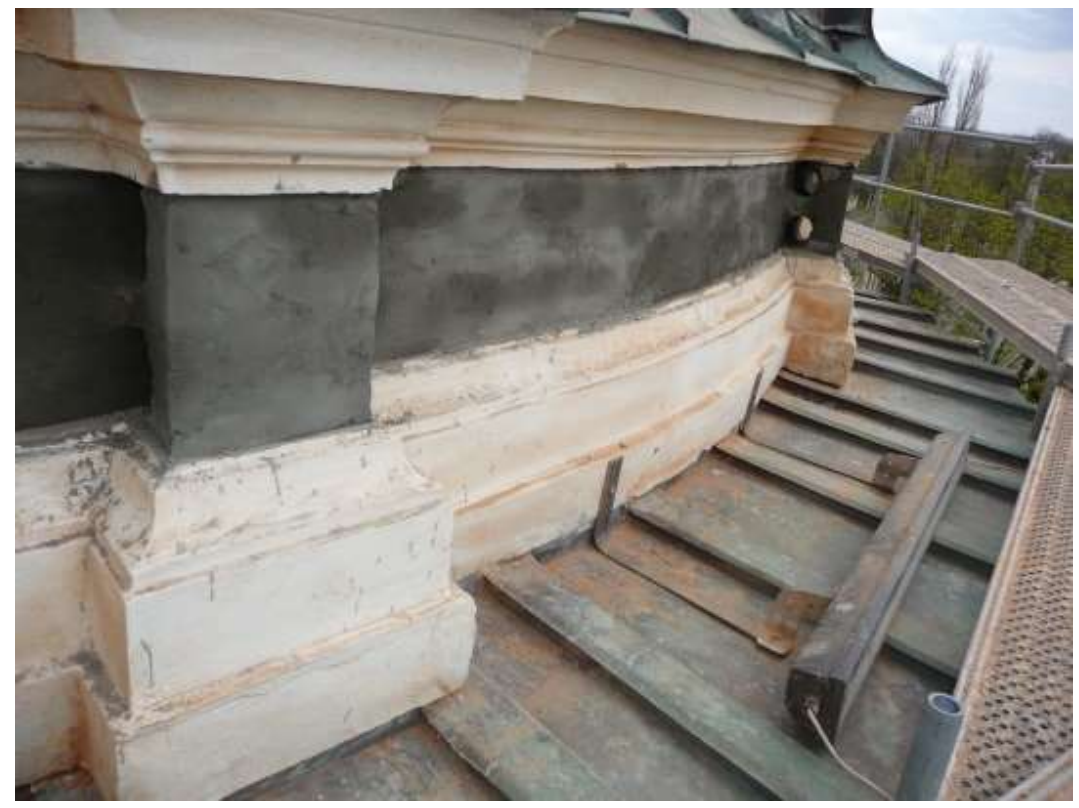

Fig. 7. The preparation of the church dome's drum for placing CFRP strips.

Drilled pilasters were reconstructed using low-tensile repair mortars, and then the previously removed cement-lime plaster on the band, which was under the tapes, was supplemented.

The next stage of repair process consisted in "sewing up" the damaged walls using spiral steel bars in the "HELFIX" system [6]. Due to the irregularity of cracks, it was recommended to reinforce the walls with horizontal bars (similarly to the barracks building in Przasnysz) as well as bars screwed under $60^{\circ}$ angle - the reinforcement scheme is shown in Fig. 8. 


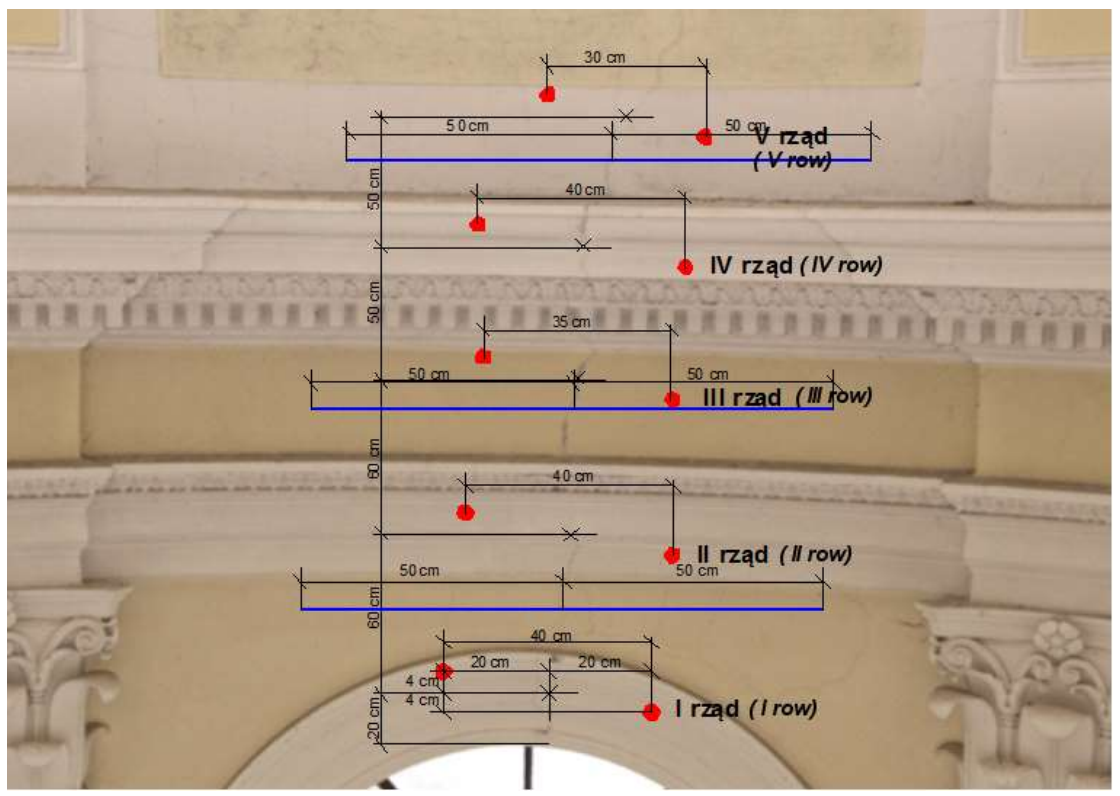

Fig. 8. Scheme of the arrangement of the reinforcement (steel spiral rods) of the cracked wall above the window arches.

The "sewing" was designed in five horizontal rows on the part of the vertical wall above the window arches. Moreover, surface reinforcement of the walls in three rows was proposed. The next stage of the repair consisted in "sewing" the damaged vaults over the windows of the dome. In this case, spiral steel reinforcement bars were also applied. Their location on the vault in the configuration of three rows is shown in Figure 9.

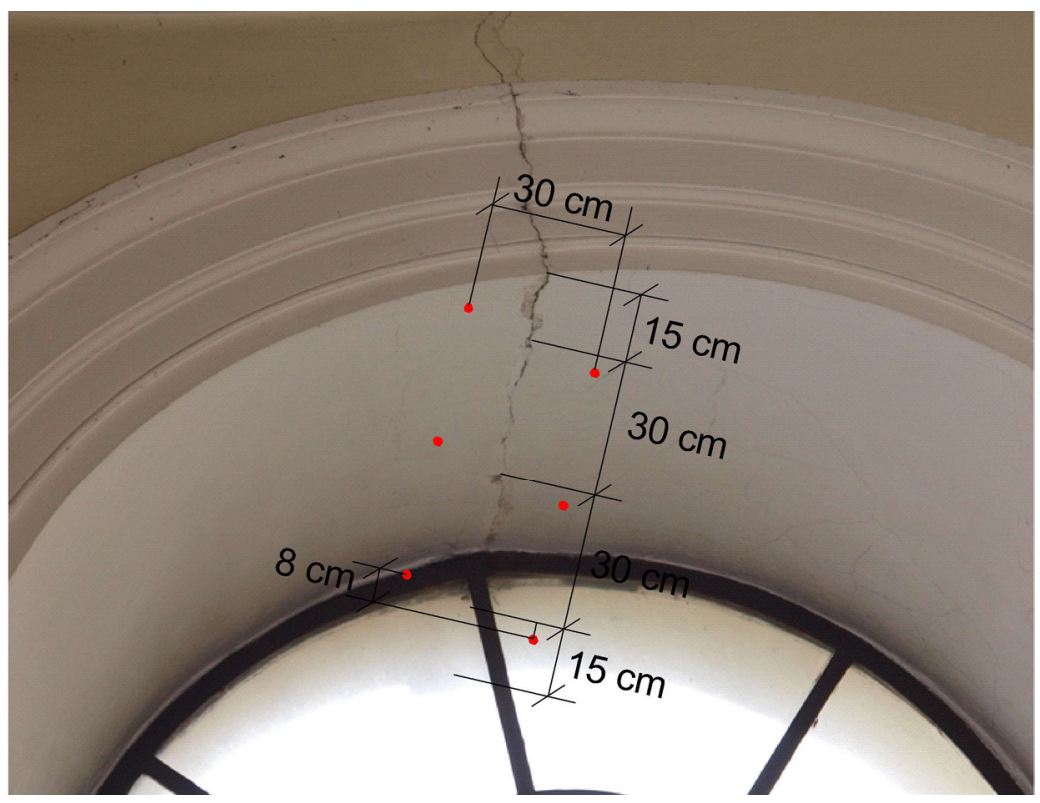

Fig. 9. Schematic layout of the reinforcement bars of the window vaults. 
The designed spacing of the reinforcement rods was at a vertical distance of $8 \mathrm{~cm}$, the length of rods of $60 \mathrm{~cm}$ in each row. The rods had to be placed symmetrically on both sides of the cracks above each window opening. The lead holes for steel rods at an angle of $60^{\circ}$ to the tangent plane to the highest point of the wall vault were also designed - Fig. 10.

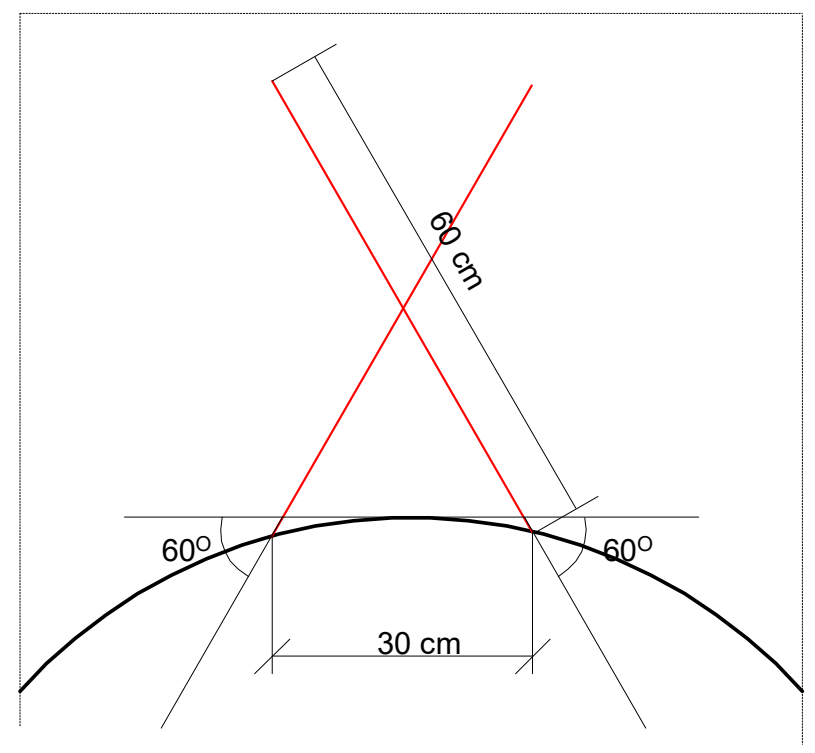

Fig. 10. Cross-section of reinforcement of the vault over window openings

After making the complete steel reinforcement system of the cracked structure of the church dome, a low-pressure injection was made using mineral repair materials, i.e. a modified white cement paste.

\section{Conclusions}

Performing renovation works on cultural heritage buildings is an extremely complex task. This applies to both regulations related to the protection of historic buildings and the technical side related to interference in the building structure. Particular attention should be paid to the parameters of built-in materials, the behaviour of building structure under operational loads and possible effects that may occur during whole building life cycle [1].

The repair in the form of surface reinforcement of the cracked and scratched gable walls of the barracks building in Przasnysz had already been recommended in the renovation design in 1997. However, no renovation works were carried out according to the recommendations, which led to further propagation and damage development. Preparing the expertise on vertical and diagonal cracks in army barracks facility in Przasnysz, "Tell-Tale" crack monitors were installed. They enabled current control of damages using crack width gauge and of propagation of observed cracks. Until commencement of the renovation works, the "Tell-Tale" crack monitors had been inspected every three months for a period of about a year. The results of conducted measurements showed that no further propagation of damage was noted. The investor has not appointed the author of this paper to prepare a building permit design on strengthening damaged masonry structure of this historic building, as well as has not informed on further construction works there.

The presented scope of the renovation works for the church of St. Anna in Wilanów can be used in the future as a model template for similar cases. Particularly, this applies to the assessment of the causes of damage, proposals and recommendations of the appropriate scope 
of actions to prevent building from the development of occurred cracks and scratches, as well as designing the most convenient and proper reinforcement method, technology and state-ofthe-art solutions. The correctness of the design solutions and calculation assumptions of this case is proved by the fact that after more than three years no damages occurred on the repaired structural elements.

When designing the reinforcement of historic buildings, it is always necessary to take into account their current technical condition as well as the parameters of built-in materials $[3,7$, 8]. It is unacceptable to use solutions that change the behaviour of the structure, as well its load distribution and reaction of applied loads. In particular, this applies to the possibility of forming additional compressive stresses and shearing stresses. In addition, when choosing a method of repair, structure should be ensured only within the range of admissible stresses.

This work was supported by the Grant No. PBS 662/2017.

\section{References}

1. R. Chmielewski, L. Kruszka, Expertises and technical opinions in the area of building structures, (WAT, 2005-2017), in Polish.

2. R. Chmielewski, L. Kruszka, Case Studies in Construction Materials, 3, (2015).

3. R. Chmielewski, L. Kruszka, J. Lalka, Biuletyn WAT, 684, 4, (2016), in Polish

4. J. Beyga, R. Chmielewski, L. Kruszka, Strengthening of St. Anna church dome in Wilanów, (Building design, Warsaw, 2009), in Polish.

5. Sika CarboDur FRP Composites for Repair and Strengthening of Structures (Sika, 2003).

6. http://www.helifix.co.uk

7. L. Binda, A. Saisi, C. Tiraboschi, Construction and Building Materials, 14, 4 (2000).

8. M.Corradi, A.Borri A.Vignoli, Construction and Building Materials 17, 5, (2003). 